\title{
A Comparison of Children's Fitness in the Northwest and Southwest of England
}

\author{
Spencer Earl Boyle \\ Faculty of Health and Life Sciences, Northumbria University, Newcastle, UK \\ Email: Spencer.boyle@northumbria.ac.uk
}

Received 16 August 2014; revised 10 September 2014; accepted 6 October 2014

Copyright (C) 2014 by author and Scientific Research Publishing Inc.

This work is licensed under the Creative Commons Attribution International License (CC BY). http://creativecommons.org/licenses/by/4.0/

c) (7) Open Access

\begin{abstract}
The data from this paper was gathered from a larger cross-sectional study examining children's physical activity participation in the Northwest and the Southwest of England. The purpose of this study was to carry out a battery of health and fitness tests with children in both areas to examine possible differences in various aspects of fitness or health by area. Heart rate recovery, flexibility, body fat, hand grip strength, upper body strength, explosive strength and agility were all measured using youth fitness tests endorsed by EUROFIT and YMCA with 59 boys and 57 girls across both areas. There were no statistically significant differences in both groups of children in hand grip strength, flexibility and agility. Statistically significant differences were noted between both groups of children in explosive strength, upper body strength and measured body fat percentage. Overall the study showed mixed results that may indicate area of residence influences aspects of fitness or activity. Further study is recommended to assess whether physical activity could play a role in the associated fitness characteristics.
\end{abstract}

\section{Keywords}

Children, Fitness Tests, Health Related Fitness, Physical Activity, Young People

\section{Introduction}

Fitness testing has been commonly used as an assessment of young people's fitness both in schools and in public health (Cale \& Harris, 2009). The health related components of one's fitness (cardio-vascular (CV), body composition, flexibility, muscle endurance, or strength) are tested because of their relation to health/disease outcomes in later life (Cale \& Harris, 2005). It could be argued that among other factors, a young person's fitness may determine how much physical activity (PA) they actually participate in. However, this is a contentious issue at present; in adults this positive relationship exists (US Dept. Health and Human Services Physical Activity and 
Health, 1996). In a pediatric population Cale \& Harris (2005) point out that circumstances such as biological, maturity, hereditary amongst others contribute to fitness level. Some of the difficulties of finding a relationship between fitness and PA lie in the sporadic nature of children's physical activity behavior (Bailey et al., 1995). Nevertheless, a weak but positive association was found between children's aerobic fitness and their PA levels by Dencker et al. (2007) in their study of 248 children from 8 to 11 years. Although at present evidence seems fragile that components of fitness or activity predict overweight in young people (Rauner, Mess, \& Wolf, 2013) more data regarding the influence of fitness on a healthy cardio-vascular disease (CVD) risk profile and future health is emerging (Twisk et al., 2002; Boreham et al., 2002; Janz et al., 2002; Baker et al., 2007; Ortega et al., 2008; Jago et al., 2011; Walker et al., 2013). Furthermore it has been noted that youth fitness tracks into adulthood Eisenmann, Wickel, Welk \& Blair (2005) and Froberg \& Anderson (2005), and there is a strong evidence base of fitness having a "protective effect" to health on overweight status in adults (Barlow, Kohl, Gibbons, \& Blair, 1995; Riddoch et al., 2009; Thorp, Owen, Nuehuas, \& Dunstan, 2011). Although many factors contribute to a young person's physical fitness, Boreham \& Riddoch (2001) have concluded that probability suggests that the ultimate benefit to adult health would be to guarantee sufficient fitness and activity in young people.

There is evidence in the existing literature that would imply that health and life expectancy differ according to the geographical location in England one resides (Black, Morris, Smith, \& Townsend, 1980; Davey Smith, Bartley, \& Blane, 1990; Davey Smith \& Egger, 1993; Office for National Statistics, 2013). It is also well documented that PA and fitness in adults have a positive effect on health therefore increasing life expectancy (Blair \& LaMonte, 2005; Duncan et al., 2005). While it has been noted that children's fitness could differ according to geographical area and is worthy of further investigation (Dollman, Norton, \& Tucker, 2002), few data are available that examine whether fitness levels differ by location in the UK in adults or children. Thus, the main aim of this study was to explore whether children in the Northwest of England (NW) displayed any different characteristics, in the aspects of fitness tested, compared with children of the same age group in the Southwest of England (SW).

\section{Methods}

\subsection{Participants}

Four comprehensive secondary schools were matched according to characteristics described in the Office for Standards in Education (Ofsted) reports two were in the Northwest of England, two in the Southwest (see Table 1 and Table 2). The schools were selected on the basis of a close match in: examination results, percentage of children on free school meals and percentage of children with special educational needs (SEN).

\subsection{Measures}

The tests used were taken from the European Fitness (EUROFIT) battery of fitness tests (Adam, Klissouras,

Table 1. Demographic characteristics of children in fitness test study by area (binary variables).

\begin{tabular}{|c|c|c|c|c|c|c|c|}
\hline \multirow{3}{*}{ Characteristic } & \multicolumn{7}{|c|}{ Area/Region } \\
\hline & \multicolumn{2}{|c|}{ Northwest $(n=57)$} & \multicolumn{2}{|c|}{ Southwest $(n=59)$} & \multirow{2}{*}{ Absolute difference } & \multirow{2}{*}{ Odds ratio (95\% CI) } & \multirow{2}{*}{$P$-value } \\
\hline & $\mathrm{n}$ & $\%$ & $\mathrm{n}$ & $\%$ & & & \\
\hline Gender (male) & 27 & $47.40 \%$ & 32 & $54.20 \%$ & $-6.80 \%$ & 1.3 (0.64 to 2.7$)$ & 0.46 \\
\hline
\end{tabular}

Note: $P$-value from chi squared test.

Table 2. Demographic characteristics of children in fitness test study by area (continuous variables).

\begin{tabular}{|c|c|c|c|c|c|c|c|c|c|}
\hline \multirow{3}{*}{ Characteristic } & \multicolumn{9}{|c|}{ Area/Region } \\
\hline & \multicolumn{3}{|c|}{ Northwest $(\mathrm{n}=57$ ) } & \multicolumn{3}{|c|}{ Southwest $\left(\mathrm{n}=57^{*}\right)$} & \multirow{2}{*}{ Un-adjusted mean difference } & \multirow{2}{*}{$(95 \% \mathrm{CI})$} & \multirow{2}{*}{$P$-value } \\
\hline & $\mathrm{n}$ & Mean & SD & $\mathrm{n}$ & Mean & $\mathrm{SD}$ & & & \\
\hline Mean age & 57 & 11.6 & 0.5 & 57 & 11.7 & 0.5 & -0.12 & $(-0.30$ to -0.05$)$ & 0.17 \\
\hline
\end{tabular}

Note: $P$-value from independent sample t-test; ${ }^{*}$ of 59 , two children failed to record their age. 
Ravazzolo, Renson, \& Tuxworth, 1988) and the Young Men’s Christian Association (YMCA) youth fitness tests (Franks, 1989). An animated record sheet was provided for the children to record their fitness scores on and the children were given a tutorial immediately prior to testing on how to record their scores. It was thought (in discussions with PE teachers and the author) that this would give the children more of a sense of involvement solely in relation to recording their results. The fitness measures have been described more fully (Boyle, 2009), however a brief description follows:

Harvard step test: a sub-maximal fitness test which predicts cardio-vascular fitness (endurance) from the rise of heart rate during moderate exercise, rather than exercise to exertion (Brouha, Health, \& Graybiel, 1943). Although only a proxy measure for "aerobic fitness", it has been reported to have a correlation to VO2 test of 0.6 to 0.8 (Montoye, Willis, Cunningham, \& Keller, 1969). Participants stepped on and off a bench for five minutes and then measured and recorded their own heart rate at one minute intervals for three minutes after the exercise (for 30 seconds, multiplied by 2 by the researcher on collection). The three pulse readings were combined using the following equation:

$$
\text { Heart rate group score }=30000 /(\text { pulse } 1+\text { pulse } 2+\text { pulse } 3)
$$

This gave a score which could be compared to a level from poor to excellent (1).

Sit and reach test: to measure flexibility in the lower back and hips. Participants sat on the floor with straight legs, leant forward and the distance they could reach past their toes in $\mathrm{cm}$ was recorded.

Skin fold thickness: to assess body fat. The thickness of skin in mm was taken with a Harpenden skin fold caliper on the back of the upper arm (tricep) and back of the same side lower leg (calf). Slaughter et al. (1988) equation was used to determine body fat as follows;

$$
\begin{aligned}
& \text { boys, \% body fat }=0.735(\text { triceps }+ \text { calf })+1.0 \\
& \text { girls, \% body fat }=0.610(\text { triceps }+ \text { calf })+5.1
\end{aligned}
$$

Hand grip strength: to measure overall strength. Participants were asked to grip a hand dynamometer which gave a measure of their strength in $\mathrm{kg}$.

Modified pull-up: to measure upper body strength. Participants performed as many pull-ups as possible on a bar positioned on a special stand so that the child's feet never left the floor.

Standing broad jump: to measure explosive strength. Participants were asked to jump as great a distance as they could (measured in $\mathrm{cm}$ ) taking off from two feet and landing on two feet.

Speed bounce test: to measure agility, muscular endurance and speed in the legs. Participants jumped over a small barrier as many times as possible in 15 seconds.

\subsection{Procedures}

The participating schools were part of a cross-sectional study examining PA, diet and quality of life (QOL) (Boyle et al., 2010a). University of Sheffield research ethics committee approval was obtained for the study and the Local Education Authority was consulted in order to gain initial contact with the state secondary schools involved. Consultation with the head teachers of the secondary schools followed this. Initially the study details were circulated in a school newspaper, which every parent received, at each school. After this process the whole schools population were given an information letter to take home with a consent slip to be returned by a parent or guardian. The parents of year 7 children received a modified letter. This letter explained that their child, if selected on the day the fitness tests were taking place, could potentially (with their consent) participate. The letter gave the option for parents and children to opt out of the physical fitness tests. However, due to the ethics of keeping the anonymity of the pupils, a limitation of the measured fitness testing was the results could not be linked to the self-reported PA from the main survey.

As the fitness testing involved seven tests and the children had a limited amount of time within their Physical education (PE) lesson, several qualified PE teachers helped with the organisation and recording of test results. Before the testing took place the teachers involved were briefed. As most PE teachers are familiar with the equipment that was used this briefing was straightforward. The children involved in the fitness tests were told of their result at the conclusion of each test and supervised to record their result on a pre-prepared result sheet. A brief procedure of how children were managed during the fitness testing has been provided elsewhere (Boyle, 
2009).

The original study population $(n=2858)$ was drawn from four schools across year groups 7 - 10 , ages 11 - 15 years (Boyle et al., 2010b). From this population a random selection of year 7 pupils (aged 11 and 12 years) (boys and girls) was taken within each school to complete seven basic fitness tests. In total there were 57 pupils ( $n=27$ boys, 30 girls) who were tested in the NW and 59 pupils ( $n=32$ boys, 27 girls) who were tested in the SW (see Table 1 and Table 2). Testing was arranged to coincide with a time in all four schools when year 7 pupils were scheduled for a PE lesson. The sample was randomly chosen, every other child on the boys' register and every other child on the girls' register. These pupils completed the fitness tests while the rest of their class took part in their normal PE lesson. The same sampling procedure was followed at all four schools involved. At this stage the children selected were again given the option of withdrawing. The results of these measures were compared cross-sectional within the NW and SW schools and also against results gained in other studies using the same aged children and test measures.

\subsection{Data Analyses}

Statistical methods were used to analyse the fitness testing outcomes. Continuous fitness testing outcomes (skin fold thickness, sit and reach score, hand grip strength, modified pull-ups, standing broad jump, speed bounce hurdles) were compared between areas using a two independent samples $t$-test. A 95\% confidence interval for the mean difference in outcomes between the areas was also calculated. A multiple linear regression model was used to adjust the between area comparison of fitness test outcomes, for the potential confounding factors of age and gender.

Binary fitness testing outcomes (optimal body fat for gender [using Slaughter et al., 1988] and above average heart rate score) were compared between the areas with a chi squared test. An odds ratio and associated 95\% confidence interval for the contrast between areas was also calculated. A multiple logistic regression model was used to adjust the between area comparison of the binary fitness test outcomes, for the potential confounding factors of age and gender.

\section{Results}

The demographic characteristics tables (Table 1 and Table 2) showed just over half the participants in the SW were boys (54.2\%) and just under half (47.4\%) in the NW were boys. The mean age of the participants was 11.6 years and 11.7 years (SD 0.5) in the NW and SW, respectively. There were no significant differences in the respondents for each area by age or gender.

Table 3 shows there were no statistically significant differences between the two groups of children in the sit and reach test, the hand grip strength test and the speed bounce hurdle test. When a multiple linear regression model was applied, to adjust the comparison between the groups for age and gender, there was also no significant difference between the children in the NW and those in the SW. The mean scores in the sum of skin fold measured, number of modified pull-ups and length of standing broad jump all showed significant differences between the NW children and the SW, with the NW group reporting a better standing broad jump score, jumping a mean of $0.3 \mathrm{~m}$ further (95\% CI 0.2 to $0.4 ; P<0.0001)$. The SW group reported a greater number of modified pull-ups, a mean of 1.01 modified pull-ups more $(95 \% \mathrm{CI}-1.3$ to $-0.57 ; P<0.0001)$ and a lower body fat, a mean of $5.1 \mathrm{~mm}$ less the NW children (95\% CI 2.7 to 7.4). These differences remained after adjusting for covariates.

Table 4 shows the proportion of boys and girls with an optimal body fat score. An optimal body fat by sum of tricep and calf skin fold for boys of this age would be 11 - $25 \mathrm{~mm}$ and girls 17 - $30 \mathrm{~mm}$ (Slaughter et al., 1988). In the NW 49.1\% had an optimal body fat score compared with $75.4 \%$ in the SW, a significant difference of $-26.3 \%$ with an OR of $0.3(95 \%$ CI 0.1 to $0.7 ; P=0.004)$. When a multiple logistic regression was applied, adjusting analysis for area (NW/SW), age and gender, area (SW) was found to have a significant positive relationship on proportion of children with an optimal body fat; OR 0.3 (95\% CI 0.1 to $0.7 ; P=0.004)$.

The proportion of pupils who achieved above an average heart rate group score was $87.7 \%$ in the NW compared with $91.5 \%$ in the SW, a non-significant difference (see Table 4). When a multiple logistic regression was applied, adjusting analysis for area (NW/SW), age and gender no significant relationship was found on the percentage of pupils who achieved at least above average heart rate group score and area (see Table 4).

The results of the eight outcomes of fitness testing can be seen in Table 3 and Table 4. 
Table 3. Main outcomes of Southwest and Northwest fitness testing (continuous data).

\begin{tabular}{|c|c|c|c|c|c|c|c|c|c|c|c|c|}
\hline \multirow{3}{*}{ Characteristic } & \multicolumn{12}{|c|}{ Area/Region } \\
\hline & \multicolumn{3}{|c|}{ Northwest $(n=1219)$} & \multicolumn{3}{|c|}{ Southwest (n = 650) } & \multirow{2}{*}{$\begin{array}{c}\text { *Mean } \\
\text { difference }\end{array}$} & \multirow{2}{*}{ (95\% CI) } & \multirow{2}{*}{$P$-value } & \multirow{2}{*}{$\begin{array}{c}{ }^{\circ} \text { Mean } \\
\text { difference }\end{array}$} & \multirow{2}{*}{ (95\% CI) } & \multirow{2}{*}{$P$-value } \\
\hline & $\mathrm{n}$ & Mean & SD & $\mathrm{n}$ & Mean & SD & & & & & & \\
\hline $\begin{array}{l}\text { Skin fold sum mm (sum } \\
\text { of calf and tricep) }\end{array}$ & 57 & 27.8 & 6.2 & 57 & 22.7 & 6.2 & 5.2 & (2.9 to 7.5$)$ & $<0.0001$ & 5.1 & (2.7 to 7.4 ) & $<0.0001$ \\
\hline Sit and reach test $(\mathrm{cm})$ & 57 & 37.4 & 6.6 & 58 & 38.1 & 6.6 & -0.72 & $(-3.2$ to 1.7$)$ & 0.56 & -0.79 & $(-3.3$ to -1.7$)$ & 0.53 \\
\hline Hand grip strength (kg) & 57 & 18.1 & 4.7 & 59 & 16.5 & 5.1 & 1.6 & $(-0.22$ to 3.4$)$ & 0.09 & 1.6 & (0.18 to 3.4$)$ & 0.08 \\
\hline $\begin{array}{l}\text { Modified pull-up (number } \\
\text { completed without rest) }\end{array}$ & 57 & 1.2 & 0.94 & 59 & 2.17 & 1.2 & -1.01 & $(-1.4$ to -0.6$)$ & $<0.0001$ & -0.94 & $(-1.3$ to -0.57$)$ & $<0.0001$ \\
\hline Standing broad jump (m) & 57 & 1.4 & 0.26 & 59 & 1.1 & 0.26 & 0.3 & (0.2 to 0.4$)$ & $<0.0001$ & 0.3 & (0.2 to 0.4$)$ & $<0.0001$ \\
\hline $\begin{array}{l}\text { Speed bounce hurdle } \\
\text { (number completed in } \\
15 \text { seconds) }\end{array}$ & 57 & 27.7 & 5.8 & 59 & 26 & 4.8 & 1.07 & $(-0.9$ to 3.05$)$ & 0.29 & 1.5 & $(-0.38$ to 3.5$)$ & 0.11 \\
\hline
\end{tabular}

Note: ${ }^{*}$ Un-adjusted simple analysis ( $t$-test); ${ }^{\circ}$ Adjusted analysis for age, gender, area (NW/SW).

Table 4. Main outcomes of Southwest and Northwest fitness test (binary data).

\begin{tabular}{|c|c|c|c|c|c|c|c|c|c|c|}
\hline \multirow[b]{2}{*}{ Characteristic } & \multicolumn{10}{|c|}{ Area/Region } \\
\hline & \multicolumn{2}{|c|}{ Northwest (n = 1219) } & \multicolumn{2}{|c|}{ Southwest $(n=650)$} & * Difference & $\begin{array}{l}\text { Odds ratio } \\
\text { (95\% CI) }\end{array}$ & $P$-value & $\begin{array}{c}\text { Adjusted } \\
\text { difference } \\
\text { odds ratio }\end{array}$ & $(95 \% \mathrm{CI})$ & $P$-value \\
\hline $\begin{array}{l}\text { Heart rate group score } \\
\text { (achieving above average) }\end{array}$ & $50 / 57$ & $87.70 \%$ & $54 / 59$ & $91.50 \%$ & $-3.80 \%$ & 0.7 (0.2 to 2.2$)$ & 0.5 & 0.6 & (0.2 to 2.2$)$ & 0.46 \\
\hline $\begin{array}{l}\text { \#Girls optimal body fat } \\
\qquad(17-30 \mathrm{~mm})\end{array}$ & $17 / 30$ & $56.70 \%$ & $23 / 26$ & $88.50 \%$ & $-31.80 \%$ & 0.2 (0.04 to 0.69$)$ & 0.009 & 0.2 & (0.04 to 0.7$)$ & 0.017 \\
\hline $\begin{array}{l}\text { \#Boys optimal body fat } \\
\text { (11 - } 25 \text { mm body fat) }\end{array}$ & 11 out of 27 & $40.70 \%$ & $20 / 31$ & $64.50 \%$ & $-23.80 \%$ & $0.4(0.1$ to 1.1$)$ & 0.07 & 0.4 & (0.1 to 1.1$)$ & 0.08 \\
\hline
\end{tabular}

Note: *Simple analysis (chi squared); Adjusted analysis for age, gender; ${ }^{*}$ Adjusted for age only in regression model.

\section{Discussion}

The main findings of this study indicate significantly more children in the SW had optimal body fat than children in the NW. The NW children had a significantly longer standing broad jump than the SW. However, the SW children demonstrated greater upper body strength in the modified pull-up test than the NW children. The findings of the study also show no relationship between area in which the children live and tests for heart rate recovery, hand grip strength, flexibility (lower back and hamstrings) and speed and agility.

The difference in body fat, standing broad jump and modified pull-up scores between these NW and SW children provides perhaps some initial evidence of differences in dimensions of fitness in children in different areas of England.

The difference in body fat was attained from a two site skin fold measure. It is acknowledged that the measurement of skin fold at only two sites is much less accurate than a fivefold measure (Malina, Bouchard, \& Bar-Or, 2004) and this must be considered as a limitation. However, the results of the skin fold test showed the children in the NW had significantly more body fat than those in the SW by a mean of $5.1 \mathrm{~mm}$ (see Table 3). As girls would be expected to have a higher body fat percentage than boys (Malina et al., 2004), the number of boys or girls tested in each area could have accounted for this; however, the mix of boys and girls in each area were not significantly different. Gender examined separately for children in the optimal body fat category, revealed 
that significantly more girls in the SW achieved 17 - 30 mm body fat than those in the NW. In the SW there were also more boys with an optimal body fat score $(11-25 \mathrm{~mm}) 64.5 \%$ compared to the NW's $40.7 \%$, although this was not significant, a trend towards significance could be seen (see Table 4). As a whole group $75.4 \%$ of children in the SW had optimal body fat scores compared to $49.1 \%$ in the NW. The score for the NW children reflects the body fat results in the Sportslinx (2003) study. This Liverpool based study used a similar skin fold test, in the same age group of children $(n=3500)$ across Liverpool and found less than half of girls and boys were in the optimal body fat category (Sportslinx, 2003). This suggests that a child from the NW area has less chance of having an optimal body fat. The reasons for this can only be speculated on as the fitness data in the present study cannot be linked to the questionnaire survey data on physical activity gathered in the same schools in Boyle et al. (2010a) due to ethical and anonymity concerns.

Although there is no direct evidence, it could be hypothesized that the children with higher body fat in the NW are less fit or participate in less activity than those with lower body fat in the SW. Research suggests that less activity is linked to more incidence of overweight; and children with less fat are likely to be fitter (Boreham \& Riddoch, 2001; Twisk 2001; Dumith et al., 2010; Gonzalez-Suarez \& Grimmer-Somers, 2011). Furthermore, Tremblay and Willms (2003), Canadian study of 7 - 11 years old found those indulging in sedentary behaviours (TV watching, computer use) were linked to being overweight and another such study Parson, Power \& Manor (2005) supports the notion that in adolescents less time watching TV equated to less frequency of being overweight. Interestingly survey data in Boyle et al. (2010b) did show children in the NW indulged in more sedentary behaviour than the SW, perhaps reflecting the higher fatness also found in the NW children. However, once more these fitness results cannot be directly linked to the Boyle et al. (2010a) survey outcomes.

In the modified pull-up test (an upper body strength test), the SW children were able to complete almost one extra pull-up (0.94) a significant difference compared to the NW. Overall although the SW children are demonstrably stronger than the NW, compared to standard reference tables (Cooper Institute for Aerobic Research, 2010) and the Liverpool Sportslinx (2003) study, the mean scores look low. The American standards for this test are 5 pull-ups for boys and 4 for girls at this age (Cooper Institute for Aerobic Research, 2010). Although a direct comparison to an American population would be inappropriate, boys in the Liverpool Sportslinx (2003) study were all achieving the standard, and the girls were just short of completing 4 pull-ups (Sportslinx, 2003). As data in this study has not been collected on type of physical activity undertaken (either habitually or during structured PE lessons) by the participants it would be speculating to associate these performances to their method of activity. Nevertheless, preadolescent boys and girls in other studies have been shown to have significant increases in local muscle endurance and upper-body strength dependent on training method employed (Faigenbaum et al., 2001). This result and the hand grip strength result, which showed over $-8 \%$ difference compared with European children Adam et al. (1988) could suggest children in both areas of England were not meeting the Department of Health recommendation of participating in strength or load bearing activities at least twice per week (DH, 2011). In terms of skeletal health more active adolescents have been shown to have denser bones than less active (Bailey \& Martin, 1994). Arguably this could have adverse implications for this sample of pupils' future health in avoiding osteoporosis which, amongst other factors, is influenced by an individual's peak bone mass accrued during late adolescence (Sallis \& Owen, 1999).

The length of standing broad jump achieved gives a marker of explosive strength. Although the SW had scored higher in other body strength tests the NW proved to have significantly longer jumps, $1.4 \mathrm{~m}$ compared with the SW's $1.1 \mathrm{~m}$. This result compared to the other tests of strength could show the children in the NW take part in more activities that require explosive strength or potentially warm-up activities in PE or PA they undertake. Faigenbaum et al. (2005) study showed jumping performance [vertical and long] in boys aged 11 declined dependent on warm-up methods used. Conversely the present result could possibly be an anomaly. However, based on the European standards the NW and SW scores are lower than the studies included in a recent metaanalysis (Tomkinson, Olds, \& Borms, 2007).

The study has several limitations. It should be acknowledged that fitness testing with children does have its limits and the assumption that those who score highly on fitness tests are more physically active is an incorrect one as a host of other factors (including hereditary and biological) account for one's fitness (Cale \& Harris, 2005). Indeed Cale \& Harris (2005) argue it is contentious whether fitness tests even provide a measure of children's fitness. This considered, past reviews from Baquet, van Praagh \& Berthoin (2003) and Jansen \& LeBlanc (2010) have used fitness as a proxy measure for recent physical activity participation. For the purposes of this study the tests were used as a crude measure of aspects of the children's physical attributes to be compared to 
the other schools involved, as this was the case any differences should be viewed with caution. All children were tested under the same conditions using the same procedures and testing equipment, therefore a fair test between the two regions was as far as possible assured. All the children involved in the tests were randomly selected, without bias, off registers and are representative of pupils in similar comprehensive secondary schools in England. However, the study took place in four schools in two regions and is not a random sample of pupils or schools. Therefore results must be interpreted cautiously and cannot be wholly representative of other schools in the NW and SW or even England.

Age and gender of the children were not significantly different. At this age (boys $=11.7$ years, girls $=11.6$ years) both girls and boys would be at different stages of maturity. Girls tend to mature earlier, and stop growing earlier; having their adolescent growth spurt approximately 12 years old (early maturing girls may have had it by this age) compared to boys who have it around 14 years old (Malina et al., 2004). Strength, motor performance and other physical tests would be influenced by body composition and physique (Malina et al., 2004). From the test measures used there is no way of knowing how physically mature the children taking part were, or if there was a mix of more physically mature children in one area compared to another. Some boys and girls go on growing into their early twenties and motivation, habitual physical activity, environment, or attitude could all add to the resulting performance (Malina et al., 2004). Nevertheless, the maturity of the participants' could arguably have had some implication on the test results. The only demographic information collected from the children was their gender and age. Therefore, the influence of socioeconomic status or ethnicity, which both have an effect on activity, if not fitness could not be taken into account in the analysis (Khunti et al., 2007; Van Sluijs, McMinn, \& Griffin, 2007). Comparison of these fitness test study results to other research in the UK or across Europe should be viewed with caution; although the same tests were used in other research studies, differences in measuring equipment and environment or conditions of tests may have existed. Indeed the results of some of the test measures may have been influenced by lack of/motivation of the pupils on the day of the tests. Slight human errors could have been recorded in the measurements of each of the fitness tests, as some of the tests were supervised and recorded by the experienced PE teachers on the day of the tests.

\section{Conclusion}

In this sample children in the SW of England had less body fat percentage and showed greater upper body strength than children in the NW, while children in the NW demonstrated greater explosive strength than those in the SW. Overall the results of these tests were somewhat mixed. However, if we are to assume that fitness levels could be a factor to account for the inequalities in health in different areas of the country (Black et al., 1980; Davey Smith et al., 1990; Davey Smith \& Egger, 1993; ONS, 2013) the variation found in these fitness test markers could indicate a difference on a broader scale. Although secondary school national curricular PE is compulsory across the country there can be differences in sports or activities employed in its delivery per school. There may even be the possibility of variations in habitual physical activity or the favoured games and physical activities practised by children in different area. These tentative results could be an indication that area of residence should be accounted for when implementing physical activity interventions. Further investigation is needed to examine potential differences in fitness test data and their relationship to other important factors (hereditary, physical activity level, socio-economic status, ethnicity and motivation, for example) across several regions in England.

\section{Funding}

This research received no specific grant from any funding agency in the public, commercial, or not-for-profit sectors.

\section{References}

Adam, C., Klissouras, V., Ravazzolo, M., Renson, R., \& Tuxworth, W. (1988). Eurofit: European Test of Physical Fitness Council of Europe. Committee for the Development of Sport Rome.

Bailey, D. A., \& Martin, A. D. (1994). Physical Activity and Skeletal Health in Adolescents. Pediatric Exercise Science, 6, 330-347.

http://journals.humankinetics.com/pes-back-issues/PESVolume6Issue4November/PhysicalActivityandSkeletalHealthinAd olescents 
Bailey, R. C., Olson, J., Pepper, S. L., Porszasz, J., Barstow, T. J., \& Cooper, D. M. (1995). The Level and Tempo of Children's Physical Activities: An Observational Study. Medicine Science in Sports Exercise, 27, 1033-1041. http://dx.doi.org/10.1249/00005768-199507000-00012

Baker, J. L., Olsen, L. W., \& Sørensen, T. I. A. (2007). Childhood Body-Mass Index and the Risk of Coronary Heart Disease in Adulthood. New England Journal of Medicine, 357, 2329-2337. http://dx.doi.org/10.1056/NEJMoa072515

Baquet, G., van Praagh, E., \& Berthoin, S. (2003). Endurance Training and Aerobic Fitness in Young People. Sports Medicine, 33, 1127-1143. http://dx.doi.org/10.2165/00007256-200333150-00004

Barlow, C. E., Kohl, H. W., Gibbons, L. W., \& Blair, S. N. (1995). Physical Fitness, Mortality and Obesity. International Journal of Obesity, 19, S41-S44.

Blair, S. N., \& LaMonte, M. J. (2005). How Much and What Type of Physical Activity Is Enough?: What Physicians Should Tell Their Patients. Archives of Internal Medicine, 165, 2324-2325. http://dx.doi.org/10.1001/archinte.165.20.2324

Boreham, C., \& Riddoch, C. (2001). The Physical Activity, Fitness and Health of Children. Journal of Sports Sciences, 19, 915-929. http://dx.doi.org/10.1080/026404101317108426

Boreham, C., Twisk, J., Neville, C., Savage, M., Murray, L., \& Gallagher, A. (2002). Associations between Physical Fitness and Activity Patterns During Adolescence and Cardiovascular Risk Factors in Young Adulthood: The Northern Ireland Young Hearts Project. International Journal of Sports Medicine, 23, s22-s26. http://dx.doi.org/10.1055/s-2002-28457

Boyle, S. E. (2009). Evaluation of Physical Activity Levels among Adolescents in the Southwest and Northwest; Consideration of Health Issues. Unpublished Doctoral Thesis, Sheffield: The University of Sheffield.

Boyle, S. E., Walters, S. J., \& Jones, G. L. (2010a). Physical Activity, Quality of Life, Weight Status and Diet in Adolescents. Quality of Life Research, 19, 943-954. http://dx.doi.org/10.1007/s11136-010-9659-8

Boyle, S. E., Jones, G. L., \& Walters, S. J. (2010b). Physical Activity, Weight Status and Diet in Adolescents: Are Children Meeting the Guidelines? Health, 10, 1142-1149. http://dx.doi.org/10.4236/health.2010.210167

Brouha, L., Health, C. W., \& Graybiel, A. (1943). Step Test Simple Method of Measuring Physical Fitness for Hard Muscular Work in Adult Men. Reviews of Canadian Biology, 2, 86.

Cale, L., \& Harris, J. (2009). Fitness Testing in Physical Education-A Misdirected Effort in Promoting Healthy Lifestyles and Physical Activity? Physical Education and Sport Pedagogy, 14, 89-108. http://dx.doi.org/10.1080/17408980701345782

Cale, L., \& Harris, J., Eds. (2005). Exercise and Young People: Issues, Implications and Initiatives. Basingstoke: Palgrave, Macmillan.

Cooper Institute for Aerobic Research (2010). Fitnessgram Test Administration Manual. Champaign, IL: Human Kinetics, 53.

Davey Smith, G., \& Egger, M. (1993). Socioeconomic Differentials in Wealth and Health: Widening Inequalities in Health. British Medical Journal, 307, 1085-1086. http://www.ncbi.nlm.nih.gov/pmc/articles/PMC1679151/ http://dx.doi.org/10.1136/bmj.307.6912.1085

Davey Smith, G., Bartley, M., \& Blane, D. (1990). The Black Report on Socioeconomic Inequalities in Health 10 Years on. British Medical Journal, 301, 373-377. http://www.ncbi.nlm.nih.gov/pmc/articles/PMC1679935/ http://dx.doi.org/10.1136/bmj.301.6748.373

Dencker, M., Thorsson, O., Karlsson, M. K., Linden, C., Wollmer, P., \& Anderson, L. B. (2007). Gender Differences and Determinants of Aerobic Fitness in Children Aged 8 - 11 Years. European Journal of Applied Physiology, 99, 19-26. http://dx.doi.org/10.1007/s00421-007-0406-y

Department of Health, DH (2011). Start Active Stay Active: A Report on Physical Activity from the Four Home Countries' Chief Medical Officers. London: Department of Health.

Dollman, J., Norton, K., \& Tucker, G. (2002). Anthropometry, Fitness and Physical Activity of Urban and Rural South Australian Children. Pediatric Exercise Science, 14, 297-312. http://journals.humankinetics.com/AcuCustom/Sitename/Documents/DocumentItem/6254.pdf

Dumith, S. C., Ramires, V. V., Souza, M. A., Moraes, D. S., Petry, F. G., Oliveira, E. S., \& Hallal, P. C. (2010). Overweight/ Obesity and Physical Fitness among Children and Adolescents. Journal of Physical Activity and Health, 7, 641-648. http://journals.humankinetics.com/jpah-back-issues/jpah-volume-7-issue-5-september/overweightobesity-and-physical-fitn ess-among-children-and-adolescents

Duncan, G. E., Anton, S. D., Sydeman, S. J., Newton, R. L., Corsica, J. A., Durning, P. E., Ketterson, T. U., Martin, A. D., Limacher, M. C., \& Perri, M. G. (2005). Prescribed Exercise at Varied Levels of Intensity and Frequency: A Randomised Trial. Archives of Internal Medicine, 165, 2362-2369. http://dx.doi.org/10.1001/archinte.165.20.2362

Eisenmann, J. C., Wickel, E. E., Welk, G. J., \& Blair, S. N. (2005). Relationship between Adolescent Fitness and Fatness and Cardivascular Disease Risk Factors in Adulthood: The Aerobics Centre Longitudinal Study. The American Heart Journal, 
149, 46-53. http://dx.doi.org/10.1016/j.ahj.2004.07.016

Faigenbaum, A. D., Bellucci, M., Bernieri, A., Bakker, B., \& Hoorens, K. (2005). Acute Effects of Different Warm-Up Protocols on Fitness Performance in Children. Journal of Strength \& Conditioning Research, 19, 376-381.

Faigenbaum, A. D., Loud, R. L., Oconnell, J., Glover, S., Oconnell, J., \& Westcott, W. L. (2001). Effects of Different Resistance Training Protocols on Upper-Body Strength and Endurance Development in Children. Journal of Strength \& Conditioning Research, 15, 459-465.

Franks, B. D. (1989). YMCA Youth Fitness Test Manual. Champaign, IL: Human Kinetics.

Froberg, K., \& Anderson, L. B. (2005). Mini Review: Physical Activity and Fitness and Its Relations to Cardiovascular Disease Risk Factors in Children. International Journal of Obesity, 29, S34-S39. http://dx.doi.org/10.1038/sj.ijo.0803096

Gonzalez-Suarez, C. B., \& Grimmer-Somers, K. (2011). The Association of Physical Activity and Physical Fitness with Pre-Adolescent Obesity: An Observational Study in Metromanila, Philippines. Journal of Physical Activity and Health, 8, 804-810.

Jago, R., Froberg, K., Cooper, A., Eiberg, S., \& Andersen, L. B. (2011). Three-Year Changes in Fitness and Adiposity Are Independently Associated with Cardiovascular Risk Factors among Young Danish Children. Journal of Physical Activity and Health, 7, 37-44.

Jansen, I., \& LeBlanc, A. G. (2010). Systematic Review of the Health Benefits of Physical Activity and Fitness in SchoolAged Children and Youth. International Journal of Behavioral Nutrition and Physical Activity, 7, 40.

http://dx.doi.org/10.1186/1479-5868-7-40

Janz, K. F., Dawson, J. D., \& Mahoney, L. T. (2002). Increases in Physical Fitness during Childhood Improves Cardiovascular Health during Adolescence: The Muscatine Study. International Journal of Sports Medicine, 23, 15-21. http://dx.doi.org/10.1055/s-2002-28456

Khunti, K., Stone, M., Bankart, J., Sinfield, P., Talbot, D., Farooqi, A., \& Davies, M. (2007). Physical Activity and Sedentary Behaviours of South Asian and White European Children in Inner City Secondary Schools in the UK. Family Practice, 24, 237-244. http://dx.doi.org/10.1093/fampra/cmm013

Malina, R. M., Bouchard, C., \& Bar-Or, O. (2004). Growth, Maturation and Physical Activity (2nd ed.). Champaign, IL: Human Kinetics.

Montoye, H. J., Willis 3rd., P. W., Cunningham, D. A., \& Keller, J. B. (1969). Heart Rate Response to a Modified Harvard Step Test: Males and Females, Age 10 - 69. Research Quarterly, 40, 153-162.

Office for National Statistics, ONS (2013). Statistical Bulletin: Healthy Life Expectancy at Birth for Upper Tier Local Authorities: England 2009-2011. Newport, Wales: Office for National Statistics.

Ortega, F. B., Ruiz, J. R., Castillo, M. J., \& Sjöström, M. (2008). Physical Fitness in Childhood and Adolescence: A Powerful Marker of Health. International Journal of Obesity, 32, 1-11. http://dx.doi.org/10.1038/sj.ijo.0803774

Parson, T. J., Power, C., \& Manor, O. (2005). Physical Activity, Television Viewing and Body Mass Index: A CrossSectional Analysis from Childhood to Adulthood in the 1958 British Cohort. International Journal of Obesity, 29, 1212-1221. http://dx.doi.org/10.1038/sj.ijo.0802932

Rauner, A., Mess, F., \& Wolf, A. (2013). The Relationship between Physical Activity, Physical Fitness and Overweight in Adolescents: A Systematic Review of Studies Published in or after 2000. BMC Pediatrics, 13, 19. http://www.biomedcentral.com/1471-2431/13/19 http://dx.doi.org/10.1186/1471-2431-13-19

Riddoch, C. J., Leary, S. D., Ness, A. R., Blair, S. N., Deere, K., \& Tilling, K. (2009). Prospective Associations between Objective Measures of Physical Activity and Fat Mass in 12 - 14 Years Old Children: The Avon Longitudinal Study of Parents and Children (ALSPAC). British Medical Journal, 339, Article ID: b4544. http://dx.doi.org/10.1136/bmj.b4544

Sallis, J. F., \& Owen, N. (1999). Physical Activity and Behavioural Medicine. London: Sage Publications.

Slaughter, M. H., Lohman, T. G., Boileau, C. A., Horswill, R. J., Stillman, M. D., Van Loan, M. D., \& Bemben, D. A. (1988). Skinfold Equation for Estimation of Body Fatness in Children and Youth. Human Biology, 60, 709-723.

Sports Linx (2003). Liverpool Sports Linx Project: Report on the Health and Fitness of Liverpool Primary and Secondary School Children. Liverpool: The City of Liverpool Council.

Thorp, A. A., Owen, N., Neuhaus, M., \& Dunstan, D. W. (2011). Sedentary Behaviors and Subsequent Health Outcomes in Adults: A Systematic Review of Longitudinal Studies, 1996-2011. American Journal of Preventive Medicine, 41, $207-215$. http://dx.doi.org/10.1016/j.amepre.2011.05.004

Tomkinson, G. R., Olds, T. S., \& Borms, J. (2007). Who Are the Eurofittest? Pediatris Fitness. Secular Trends and Geographic Variablility. Medicine and Sports Science, Basel, Karger, 50, 104-128. http://dx.doi.org/10.1159/000101355

Tremblay, M. S., \& Willms, J. D. (2003). Is the Canadian Childhood Obesity Epidemic Related to Physical Inactivity? 
International Journal of Obesity, 27, 1100-1105. http://dx.doi.org/10.1038/sj.ijo.0802376

Twisk, J. W. R. (2001). Physical Activity Guidelines for Children and Adolescents: A Critical Review. Sports Medicine, 31, 617-627. http://dx.doi.org/10.2165/00007256-200131080-00006

Twisk, J. W. R., Kemper, H. C. G., \& Van Mechelen, W. (2002). The Relationship between Physical Fitness and Physical Activity during Adolescence and Cardiovascular Disease Risk Factors at Adult Age: The Amsterdam Growth and Health Longitudinal Study. International Journal of Sports Medicine, 23, 8-14. http://dx.doi.org/10.1055/s-2002-28455

US Department of Health and Human Services Physical Activity and Health (1996). A Report of the Surgeon General. Atlanta, GA: Department of Health and Human Services, Centres for Decease Control and Prevention, National Centre for Chronic Disease Prevention and Health Promotion, 61-102.

Van Sluijs, E. M. F., McMinn, A., \& Griffin, S. J. (2007). Effectiveness of Interventions to Promote Physical Activity in Children and Adolescents: Systematic Review of Controlled Trials. British Medical Journal, 335, 703.

http://dx.doi.org/10.1136/bmj.39320.843947.BE 
Scientific Research Publishing (SCIRP) is one of the largest Open Access journal publishers. It is currently publishing more than 200 open access, online, peer-reviewed journals covering a wide range of academic disciplines. SCIRP serves the worldwide academic communities and contributes to the progress and application of science with its publication.

Other selected journals from SCIRP are listed as below. Submit your manuscript to us via either submit@scirp.org or Online Submission Portal.
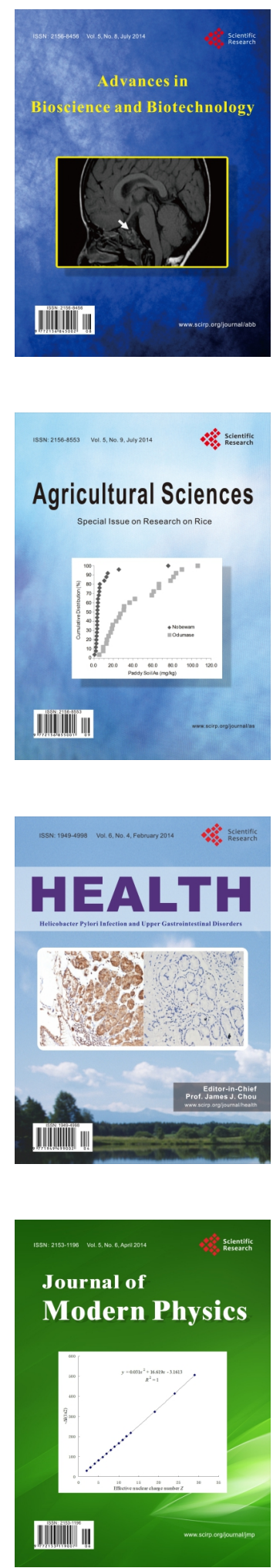
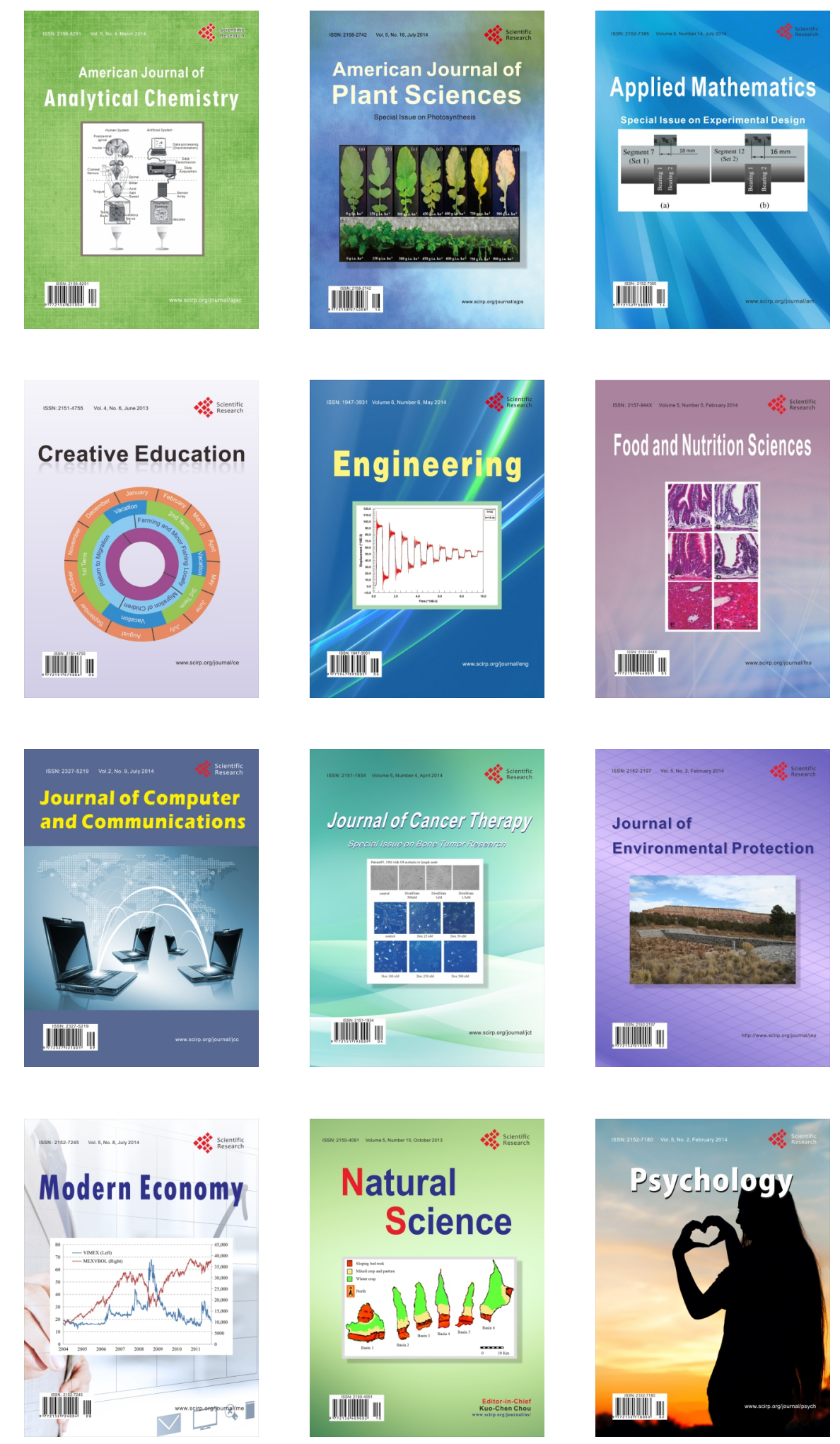